\title{
Correction to: On Automatic Loop Data-Mapping for Distributed-Memory Multiprocessors
}

\section{J. Torres, E. Ayguadé, J. Labarta, J.M. Llaberia and M. Valero}

Correction to: J. Torres et al., On Automatic Loop DataMapping for Distributed-Memory Multiprocessors, DOI 10.1007/BFb0032934

The author name was incorrectly captured in this chapter. Author name J.M. Liaberia should read as J.M. Llaberia. This has been corrected.

The updated online version of the original chapter can be found at https://doi.org/10.1007/BFb0032934 